\title{
Critical Discourse Analysis of Modal Verbs in 2017 BRICS Talk-A Perspective of Functional Systemic Grammar
}

\author{
Xuemei Lu \\ School of Foreign Languages, Guangzhou College of Commerce, Guangzhou, China \\ Email: 1129498654@qq.com
}

How to cite this paper: Lu, X. M. (2022). Critical Discourse Analysis of Modal Verbs in 2017 BRICS Talk-A Perspective of Functional Systemic Grammar. Open Journal of Social Sciences, 10, 67-79.

https://doi.org/10.4236/jss.2022.103005

Received: February 14, 2022

Accepted: March 6, 2022

Published: March 9, 2022

Copyright $\odot 2022$ by author(s) and Scientific Research Publishing Inc. This work is licensed under the Creative Commons Attribution International License (CC BY 4.0).

http://creativecommons.org/licenses/by/4.0/

\section{(c) (i) Open Access}

\begin{abstract}
Modality received considerable attention from both a synchronic and diachronic perspective. Modality can be realized by finite modal operators and modal adjuncts. This paper tries to analyze modal verbs used by five hosts of different nations in the 2017 BRICS Talk, a special program made by CGTN ahead of the ninth BRICS Summit. Based on systemic functional grammar (SFG) on the sub-systems of modality, five small corpora are established and quantified to investigate the number, frequency and distribution of modal verbs. Through the corpus-based research, the author finds that there are similarities and variations on the use of modal verbs in different anchors, which reveals different power relations behind their utterances. The findings are interpreted in terms of individual, cultural differences between the five moderators. This paper contributes to research that probes into power relations in the context of media from a CDA perspective and provides further understanding of modality in the public discourse.
\end{abstract}

\section{Keywords}

Modal Verbs, Critical Discourse Analysis (CDA), BRICS Talk, Systemic Functional Grammar (SFG)

\section{Introduction}

BRICS Xiamen Summit grabbed much worldwide attention in 2017, marking a new stage that BRICS cooperation entered. Before the ninth BRICS Summit was held in the Chinese city of Xiamen, for the very first time in history, CGTN invited four other TV stations from the other BRICS countries to come to Beijing and produce a one-hour special program looking at the opportunities and chal- 
lenges facing BRICS nations, as well as other developing countries. Liu Xin from CGTN, Peter Lavelle from RT, Vishnu Som from NDTV, Chriselda Lewis from the South African Broadcasting Corporation, Marcelo Torres from Brazilian Television System SBT, as well as a group of senior representatives from each BRICS country and other nations, had a heated discussion that covered topics ranging from politics, national defense, economics, and climate change. Their topic was also extended to how to build a global community with a common destiny. This program is the first to host a five-country BRICS talk, which makes it possible to listen to the opinions of other BRICS nations. Five hosts come from different ideological backgrounds, which provide an excellent date to investigate how ideologies are discussed and negotiated as well as how power relations are asserted from the perspective of Critical Discourse Analysis (CDA). Despite a substantial body of research exploring CDA, there is very little literature on public programs between hosts of different nations. This paper is intended to fill the gap by focusing on five hosts of BRICS countries.

$\mathrm{CDA}$ is an approach used to reveal the hidden discursive factors in terms of power, ascendency, inequality and bias. It explores how these factors are sustained and rebuilt among the relevant social, political and historical contexts (Van Dijk, 1988). Compared with traditional discourse analysis, CDA is distinguished by the close relationship between discourse and power. Targeted at public discourse, $\mathrm{CDA}$ has become an effective tool to investigate the relationship among language, power and ideology of political speeches. Moreover, CDA is inextricably linked with Systemic Functional Linguistics (SFL) (Young \& Harrison, 2004). On one hand, SFL provides the theoretical foundation and analytical method for CDA (Fowler et al., 1979; Fairclough \& Wodak, 1997; Martin \& Rose, 2007). On the other, the two areas of study have supported and supplemented each other and become complementary perspectives and analytical paradigms in discourse analysis (Miao, 2016). According to Halliday (1994), three meta-functions of systemic functional grammar are realized through different means at the lexical-grammatical level. The interpersonal function is mainly associated with the mood and modality system. Modality is defined by SFL as a speaker's judgments on or attitudes toward proposition or proposal, which are usually represented by modal verbs. Therefore, it is of great significance to study power relations hidden in the modality use. Using UAM Corpus Tool, this paper endeavors to conduct a critical discourse analysis of the different attitudes or judgments of five hosts in BRICS Talk based on the systemic functional grammar so as to reveal the hidden power relations and ideologies.

The innovation of this paper partly lies in its new textual data and topic. In addition, the research corpus is based on five corpora, which are extended and more distinct than ever before. Overall, this article is of great value to the literature. Firstly, it adds to the body of research that probes into CDA from the media discourse perspective. Secondly, this study is a new attempt to integrate CDA with modality under Systemic Functional Linguistics. Thirdly, the research provides further understanding of modality in the public discourse, testifies the ef- 
fectiveness of the relationship between CDA and SFL, and examines the hidden power relations in language by analyzing the usage of modal verbs.

\section{Literature Review}

\subsection{Critical Discourse Analysis}

CDA originates from Critical Linguistics, a term first adopted by a group of scholars working at the University of East Anglia (Fowler, Hodge, Kress, \& Trew, 1979). It covers two aims: firstly, to use the tools provided by linguistic theories to uncover the linguistic structures of power in texts; secondly, to make the discipline of linguistics itself more accountable, more responsible, and more responsive to questions of social equity (Hodge \& Kress, 1974; Fowler et al., 1979; Fowler, 1987; Fairclough, 1989). Van Dijk (2001) pointed out that CDA aims to provide a different analytical framework and applicable model throughout the realm. Put it simply, CDA is conceptualized by Van Dijk (2001: p. 352) as "a type of discourse analytical research that primarily studies the way social power abuse, dominance, enacted and reproduced and resisted by text and talk in the social and political context". Wodak and Meyer (2001: p. 2) define CDA as "fundamentally concerned with analyzing opaque as well as transparent structural relationships of dominance, discrimination, power and control as manifested in language". All these definitions give us insights into CDA studying complicated social and political phenomena, as well as exploring the ideological implications and power relations based on the analysis of language use.

Currently, there are a variety of methodologies regarding CDA research. Apart from previous methods like historical-discourse analysis and socio-recognition analysis, some new methods are put forward such as dispositive analysis, social actors analysis, and dialectical relational analysis (Wodak \& Meyer, 2009). Although these research methods are not completely systematic and effective, they witness the tremendous progress that CDA has made in diving into the relationship between discourse and socio-ideology. One of the recent highlights in $\mathrm{CDA}$ development is its integration with corpus and cognitive linguistics ( $\mathrm{Li} \&$ $\mathrm{Li}, 2014)$. There has been a scarcity of methods of corpus collection in CDA research (Meyer, 2001). Corpus linguistics, a good instrument to investigate text analysis, has received wider attention. For example, some scholars strive to analyze the ideologies in the text of political news and emphasize the importance of corpus to disclose the relationship between language and power relation (Stubbs, 1996; Baker et al., 2008; Kandil, 2009; Salama, 2011). Some Chinese scholars (Qian, 2010; Guo, 2011; Tang, 2011) also combine corpus with CDA and explore how corpus data is gained and serves CDA. Besides, other scholars try to study CDA from the perspective of cognitive linguistics. Hart (2010) could be the first scholar to systematically apply cognitive linguistics to CDA. His contribution to $\mathrm{CDA}$ is that he explains the correlation between cognitive science and CDA. Chinese scholars also have carried out some studies on this aspect and made some achievements. Their research just sheds light on critical analysis on meta- 
phor (Ji \& Chen, 2007; Zhu, 2009; Zhang, 2011), review on cognitive discourse analysis (Shen \& Xin, 2016) and analysis on the integration between cognitive linguistics and CDA (Zhang \& Jiang, 2008; Zhang, 2015).

Although CDA research has made strides, it is also confronted with some problems. Since it takes text as its research unit and as the basis of ideology analysis, it remains disputable in the academic field. Widdowson (1998) holds the belief that CDA sets no clear boundary for concepts, disciplines, and methodologies. Likewise, Xin (2004) posited that concept, method, and result remain to be questioned. Stubbs (1997) stated 11 problems concerned with whether CDA is clear, objective, reliable and verifiable. O'Halloran (2003) criticized CDA for its dependence on symbolism while Blommaert (2005) pointed out that it counts on SFL too much and is limited to western countries.

\subsection{Systemic Functional Grammar and Modality}

One of the major contributions that Halliday has made to linguistic analysis is his development of a detailed functional grammar of modern English (Halliday, 1994), showing how simultaneous strands of meanings (the ideational, interpersonal, textual metafunctions) are expressed in clause structures. The ideational function "serves for the expression of the speaker's experience of the real world, including the inner world of his consciousness" (Halliday, 1970: p. 143). Language performs the interpersonal function to "establish and maintain social relations: for the expression of social roles and for getting things done by means of the interaction between one person and another" (ibid). Textual function refers to the fact that "language has to provide for making links with itself and with features of the situation in which it is used" (ibid). Furthermore, SFL identifies three key dimensions of the situations as having significant and predictable impacts on language use. These three dimensions consist of the register variables of mode (amount of feedback and role of language), tenor (role relations of power and solidarity) and field (topic or focus of the activity) (Eggins, 2004).

With regard to interpersonal function, Simpson (1993) believes that this metafunction deals with people's attitudes, viewpoints and thoughts. It is an effective way to represent the role of ideology in discourse. Thus, language builds and maintains social relationships by means of interpersonal function, which is realized by modality and mood. According to Halliday \& Matthiessen (2014), intermediate degrees between the positive and negative polarity are known collectively as modality. What the modality system does is to construe the region of uncertainty that lies between "yes" and "no". Halliday \& Matthiessen (2014: p. 172) gives such a definition of modality as "speaker's judgment, or request of the judgment of the listener, on the status of what is being said". Modality originates from modal logic, a branch of former linguistics. Most research only touches on a semantic level like modals, modal verbs, modal auxiliary verbs (Feng, 2011). In this respect, Lakoff (1973) delved into the truth-conditional proposition from the angle of hedges, and its fundamentals have a close relationship with modal 
logic. In terms of its classification, different linguists hold different opinions. Lyons (1977) categorizes modality into epistemic and deontic modality while Palmer (1990) adds the dynamic modality to the types on this basis. Overall, these different divisions are used to describe the same meaning. In the meantime, some scholars like Sweetser (1990) distinguish root modality from epistemic one. There is no accurate definition and categorization of modality in the linguistic field yet. This can be explained by the fact that research on root modality is insufficient and it fails to take logic necessity and probability into consideration (Sweetser, 1990). Noticeably, Halliday \& Matthiessen (2014) assert that modality is divided into modalization and modulation. The scale of modalization includes probability and usuality while modulation involves obligation and inclination. As Halliday and Mattiessen (2004: pp. 147-150) present it,

Probability: The speaker expresses judgments as to the likelihood or probability of something happening or being;

Usuality: The speaker expresses judgments as to the frequency with which something happens or is. Moreover, Halliday also differentiates proposition from proposal. Logicians only pay attention to "proposition" used to negotiate information, while Halliday also regards "proposal" used to exchange goods and services as a part of modality. Thus, Halliday's systemic functional grammar that gives a full description of modality system, in a sense, is more appropriate to analyze the discourse analysis compared with other theories (Huang, 2001).

\section{Research Methods and Questions}

To explore the hidden power relations and ideologies through five moderators in BRICS Talk, the author of this paper conducted a small corpus-based study on the modality distribution from the perspective of modal verbs and critical discourse analysis is adopted. To this end, three questions are put forward as follows:

1) Do these five corpora share similarities and differences in the overall number and frequency of modal verbs?

2) Are there variations in the types of modality employed by these five hosts?

3) Are there differences in the power relations reflected in the discourse of five hosts?

In this research, the author used the UAM Corpus Tool available online (http://www.corpustool.com/) to annotate modal verbs and then calculated the frequencies and ratios of them since it is a corpus tagging and analyzing software mainly aimed at system functional linguistics studies. Firstly, since the live program is English-context and official subtitles are not available, we organized five groups of English graduate students (about 30 students) to transcribe this video and finally, we together checked the transcription which was finally testified by native speakers of English. Then the author selected and established five texts by five hosts from the whole transcription, totaling 6014 words calculated by Microsoft Word. In particular, there are approximately 864 words in Chriselda's 
text, 1766 words in Liu's text, 694 words in Marcelo's text, 1528 words in Peter's text and 1162 words in Vishnu's text. To help readers understand better, we drew the following Table 1.

Before tagging on the UAM, the author edited a scheme based on Halliday's theory on modality (see Figure 1).

Since there is still room for improvement in automatic annotations, manual annotations are adopted. The UAM is also used to extract tagged data and calculate numbers and frequencies of modal verbs. Based on these statistical data, this paper can identify the specific features of modal verbs. Modality can be realized by finite modal operators and modal adjuncts (Halliday \& Matthiessen, 2014). The finite modal operators refer to such modal verbs as can, could, may, might, should, must, etc., while the modal adjuncts include mood adjuncts and comment adjuncts (ibid). In the meantime, such expressions as "I think", "I suppose", and "I am sure" are called grammatical metaphors or metaphors of modality, which belongs to mood adjuncts (Halliday \& Matthiessen, 2004). In this research, we only take account of modal verbs in the process of tagging. According to Biber et al. (1999: p. 73), modal verbs can be classified into three types:

1) Central modal verbs: can, could, may, might, must, shall, should, will, would.

2) Marginal modal verbs: dare (to), need (to), ought (to), used to.

3) Semi-modal verbs: have to, (had) better, (have) got to, be supposed to, be going to.

Therefore, based on the modal verbs' category given by Biber et al. and types of modality, this paper established a small corpus through UAM Corpus Tool to find out the differences and similarities of modality.

\section{Results}

After making annotations of these three types of modal verbs, we finally obtained the analysis results listed in Table 2.

Table 1. Total number of five texts.

\begin{tabular}{cccccc}
\hline Name & Chriselda & Liu & Marcelo & Peter & Vishnu \\
\hline Nationality & South Africa & China & Brazil & Russia & India \\
Total number & 864 & 1766 & 694 & 1528 & 1162 \\
\hline
\end{tabular}

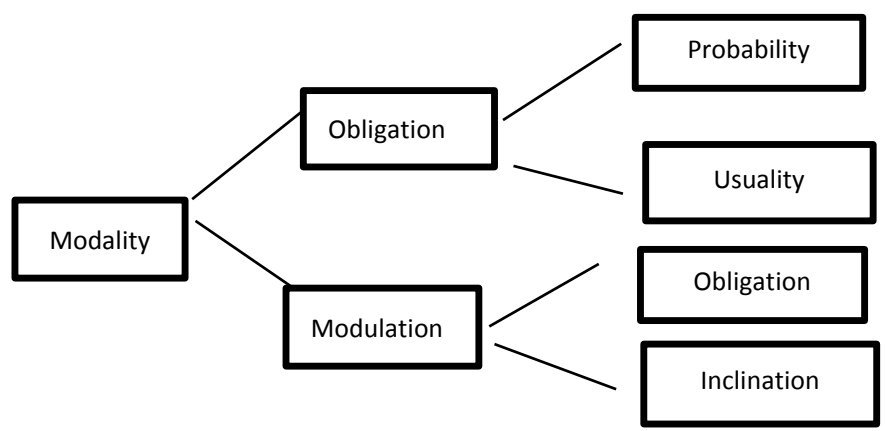

Figure 1. Scheme for annotation. 
Table 2. Features of five texts.

\begin{tabular}{ccccccccccc}
\hline Text & \multicolumn{2}{c}{ Chriselda } & \multicolumn{2}{c}{ Liu } & \multicolumn{2}{c}{ Marcelo } & \multicolumn{2}{c}{ Peter } & \multicolumn{2}{c}{ Vishnu } \\
\hline Feature & $\mathrm{N}$ & percent & $\mathrm{N}$ & percent & $\mathrm{N}$ & percent & $\mathrm{N}$ & percent & $\mathrm{N}$ & percent \\
\hline Total Units & 22 & \multicolumn{3}{c}{34} & \multicolumn{3}{c}{14} & \multicolumn{2}{c}{49} & \\
Modality & $\mathrm{N}=22$ & $\mathrm{~N}=34$ & $\mathrm{~N}=14$ & $\mathrm{~N}=49$ & $\mathrm{~N}=23$ \\
Modalization & 5 & $22.73 \%$ & 11 & $32.35 \%$ & 6 & $42.86 \%$ & 5 & $10.20 \%$ & 8 & $34.78 \%$ \\
Modulation & 17 & $77.27 \%$ & 23 & $67.65 \%$ & 8 & $57.14 \%$ & 44 & $89.80 \%$ & 15 & $65.22 \%$ \\
Modalization & $\mathrm{N}=5$ & $\mathrm{~N}=11$ & $\mathrm{~N}=6$ & $\mathrm{~N}=5$ & $\mathrm{~N}=8$ \\
Probability & 5 & $22.73 \%$ & 11 & $32.35 \%$ & 6 & $42.86 \%$ & 5 & $10.20 \%$ & 15 & $34.78 \%$ \\
Usuality & 0 & $0.00 \%$ & 0 & $0.00 \%$ & 0 & $0.00 \%$ & 0 & $0.00 \%$ & 0 & $0.00 \%$ \\
Modulation & $\mathrm{N}=17$ & $\mathrm{~N}=23$ & $\mathrm{~N}=8$ & $\mathrm{~N}=44$ & $\mathrm{~N}=15$ \\
Obligation & 9 & $40.91 \%$ & 6 & $17.65 \%$ & 2 & $14.29 \%$ & 25 & $51.02 \%$ & 8 & $34.78 \%$ \\
Inclination & 8 & $36.36 \%$ & 17 & $50.00 \%$ & 6 & $42.86 \%$ & 19 & $38.78 \%$ & 7 & $30.43 \%$ \\
\hline
\end{tabular}

Table 2 results represent the feature coding of five texts. Through the comparison of five texts, we can find that the expression of modulation far exceeds that of modalization in number and frequency. In detail, Peter uses most units of modal verbs whereas Marcelo uses least. Obviously, Peter's usage of modal verbs is disproportionate to the total words he speaks. On the whole, Marcelo's text takes the highest percentage in terms of modalization though its total unit of modal verbs is the smallest. On the contrary, the text of Peter who uses modal verbs most, however, accounts for the lowest percentage in this meaning. As for modulation, it is apparent that the proportion of Peter is much higher than that of other hosts, especially Marcelo. As such, we have good reason to believe that Peter rather than other hosts tends to employ modal verbs, particularly those expressing modulation. Marcelo has a propensity for using modal verbs which express modalization. Regarding probability, it is not difficult to find that the result is the same as the modalization result in that usuality is generally represented by mood adjuncts like usually, sometimes, never, always, etc, but this study is focused on modal verbs. Moreover, no modal verbs are showing the meaning of usuality through our search and analysis. As for obligation, Peter's frequency is still overwhelming while Marcelo's usage is fairly far and few between. Another subtle difference is that modal verbs used to express inclination are employed at a higher percentage in Liu's text than other speakers. This may be explained by the fact that China is the host country of this BRICS Summit and Chinese people tend to favor modesty and show politeness.

According to Halliday \& Matthiessen (2014), modal verbs are a subjective and implicit means on the speaker's part. There is a system of three values on modality, modal verbs included. The diagram of three values on main modal verbs is listed below (see Table 3).

Then we use UAM Corpus Tool to search the most frequently-used words and calculate their percentage. The following table illustrates the distribution of modal verbs in the five texts (see Table 4 ). 
Table 3. Values of main modal verbs.

\begin{tabular}{cc}
\hline values & modal verbs \\
\hline high & must, ought to, have to, need to \\
median & will, would, should, be to \\
low & might, may, could, can \\
\hline
\end{tabular}

Table 4. Distribution of main modal verbs in five texts.

\begin{tabular}{cccccccccccccc}
\hline modal verbs & \multicolumn{2}{c}{ total } & \multicolumn{2}{c}{ Chriselda } & \multicolumn{2}{c}{ Liu } & \multicolumn{2}{c}{ Marcelo } & \multicolumn{2}{c}{ Peter } & \multicolumn{2}{c}{ Vishnu } \\
\hline wording & $\mathrm{N}$ & $\%$ & $\mathrm{~N}$ & $\%$ & $\mathrm{~N}$ & $\%$ & $\mathrm{~N}$ & $\%$ & $\mathrm{~N}$ & $\%$ & $\mathrm{~N}$ & $\%$ \\
can & 32 & 22.54 & 3 & 13.64 & 8 & 23.53 & 5 & 35.71 & 9 & 18.37 & 7 & 30.43 \\
will & 24 & 16.90 & 6 & 27.28 & 11 & 32.35 & 1 & 7.14 & 3 & 6.12 & 3 & 13.05 \\
need to & 17 & 11.97 & 5 & 22.73 & 2 & 5.88 & 0 & 0.00 & 5 & 10.20 & 5 & 21.74 \\
have to & 16 & 11.27 & 0 & 0.00 & 2 & 5.88 & 0 & 0.00 & 14 & 28.57 & 0 & 0.00 \\
would & 12 & 8.45 & 1 & 4.55 & 3 & 8.82 & 3 & 21.43 & 1 & 2.04 & 4 & 17.39 \\
should & 8 & 5.63 & 0 & 0.00 & 2 & 5.88 & 2 & 14.29 & 2 & 4.08 & 2 & 8.70 \\
\hline
\end{tabular}

Since some modal verbs like "be supposed to" and "could" are scarcely used in the whole text, the table does not include them but shows modal verbs occurring most frequently such as "can", "will", "need to", "have to", "would", and "should". It is found that both Chriselda and Liu utilize "will" more than other modal verbs as well as other male hosts. Interestingly, Chriselda never uses modal verbs like "have to" and "should". That is, she seems to have a particular preference for median-value modal verbs, which is also true of Liu. We can also see that "can" occupies a larger proportion in Marcelo's text, which proves that he is inclined to use low-value modal verbs to express his intentions and judgments. Another discovery is that such modal verbs as "have to" and "need to" do not appear in his text. It demonstrates that Marcelo prefers to use modal verbs expressing probability and inclination rather than obligation, which is coincident with previous findings. It is also found that "have to" is used most widely and "would" is little mentioned in Peter's whole text. This is a good mirror of his inclination to utter high-value modal verbs that convey the meaning of obligation. As for Vishnu, he uses significantly more "can" than other modal verbs, which is a metaphor for his predilection for low-value modal verbs.

Overall, the usage of "can" makes up a larger proportion than that of other modal verbs, which turns out that low-value modal verbs are most favored by speakers. In addition, median-value modal verbs like "will" and "would" are also often mentioned in their utterance since they are distributed evenly in the five texts. In a word, the amount of low and median value modals is slightly higher than that of high-value modals. However, high-value modal verbs like "have to" and "need to" are tremendously employed by Peter, which leads to the increase of total units. Different modal values, in a sense, can reflect different social statuses and power relations. 


\section{Discussion}

In the last part, we reviewed the experiment results of contrastive analysis. This part strives to analyze the power distribution hidden in their dialogue. As Foucault pointed out, where there is a discourse, there is power. Power is the driving force that operates discourse (Schneck, 1987). Hence, some examples are chosen in this section. Organized by CGTN, this unprecedented TV program invites four co-hosts except for Chinese host Liu to speak their voice about the development of BRICS under the new circumstances throughout the world. Their dialogue, to some extent, can reflect the underlying power relations. According to the given information of these five hosts, the power distribution can be presented as Marcelo $\approx$ Vishnu $<$ Liu $\approx$ Chriselda $<$ Peter.

Marcelo and Vishnu prefer to use low and median value modals in their discourse, which results in a large percentage of probability and inclination. Let's take a closer look at some examples selected from their texts.

1) But what kind of tracks this American position can post in the international community. (Marcelo)

2) And I think our people, the people from Brazil, from China, South Africa, all of our people should have the opportunity to have this kind of information more often. (Marcelo)

3) We don't see you as a threat. We would like you to be a friend. (Vishnu)

4) No, she's asking an important question about what can be done in terms of mechanism. (Vishnu)

Here, "can" is nearly used in declarative sentences which often signifies probability or inclination. Marcelo and Vishnu try to use low-value modal verbs to express uncertainty and avoid being absolute. For one thing, these models can be used to mitigate their assertions; for another, they can also be an ideal way to show politeness and save the speaker's face. Different modal verbs can play different semantic functions. According to the classification of Palmer (1990), there is a tendency that Brazil's and India's hosts employ more epistemic and dynamic modality to expound their opinions. Furthermore, they would like to speak less and listen to other voices. Equal as the interpersonal relationship between five hosts seems, Marcelo and Vishnu are positioned in a subordinate status through their discourse. Evidently, they do not control or command others and are relatively powerless in the talk.

Chriselda and Liu tend to use low and median modal verbs like "can", "will", but they will also resort to "need to" in order to arouse the feelings of the audience by explaining what BRICS countries should do next. For example:

1) And we think that once this BRICS summit does get underway, these leaders will need to find tangible solutions. (Chriselda)

2) ...but it really brings back to what we've all been saying, about the fact that we need to tell our own stories, we cannot have other people telling our stories, and it gives a complete, different view of exactly what our countries are about. (Chriselda) 
3) Vishnu, you are defense editorial principal anchor from NDTV, so naturally you probably will be looking more at security, national defense and deadline. (Liu)

4) But we need to believe in the same thing, for instance, openness, inclusiveness, cooperation and win-win. (Liu)

Chriselda and Liu are more likely to employ low and median value modal verbs more as a way of elaborating their views. This preference is similar to that of Marcelo and Vishnu. However, these two female moderators, particularly Chriselda use more deontic modality to show obligation or responsibility. This difference may be caused by women's desire for discourse power under feminism (Zhao, 2001). According to Mazibuko (2017), patriarchy dominates the social relations in South Africa currently, but a few women manage to mediate power control. In the meantime, Liu, the leading host of this show, acts as a good coordinator during the whole process. Nevertheless, she endeavors to guide this talk rather than persuade to control others even though she has the right to do so. This may be closely related to Chinese collective culture, which favors group interests and modesty rather than disputation (Hofstede, 2001). As such, we maintain the idea that Chriselda and Liu fail to be powerful in their talk.

Compared with the above four hosts, Peter uncovers his great power through his speech. Here are some examples:

1) And we have to use the rule of law, facts, verifiable facts and always try to stay away from sermonizing. (Peter)

2) Well, we can...we can and we have to do it, because your algorithm can disappear. (Peter)

It is noted that Peter even uses "have to" fourteen times to express necessity or obligation. He tends to tell people what to do and seems to firmly believe that his viewpoints are right. Not only does he take the initiative to voice out on his part, but also he takes to interrupt others in a bid to give comments. Based on Hofstede's (2001) dimensions, Russia features high power distance, which puts an emphasis on social status and power. Thus, this cultural factor may account for his power control during the conversation.

\section{Conclusion}

To sum up, the distribution of modal verbs is somewhat similar across the five corpora, with modulation receiving about $70 \%$ of modality. Marcelo contributes least to the modulation expression while Peter contributes most to it. In general, the scale of inclination outnumbers that of obligation, which demonstrates that hosts are more likely to express willingness using modal verbs. Moreover, there are some subtle differences in the value of modals. On the whole, hosts are inclined to adopt low and median value modal verbs to give expression to their uncertain feelings. This is partly because the words used by the public figures can represent national images and they will lower their stance and hedge their assertions. However, Peter attracts extra attention in that high-value modal verbs 
are abundant in his language.

In addition to the variations in the usage of modal verbs, this study also reveals the hidden relationship among discourse, power and ideology through critical discourse analysis. In terms of power relations, Peter is more powerful than other anchors in discourse. By contrast, Marcelo gives such an impression that he is too weak in discourse to affect the talk. Despite the same length of time, five corpora are distinguishable: from the number of words to the frequency of modal verbs. This may be inextricably associated with cultural and linguistic factors since they come from different countries and they are not native speakers of English. Besides, their discourse also reflects and construes ideology. Their dialogue is a battle between ideology and power. When they state views, they will undoubtedly allow for national interests, thus their words are fraught with ideological nature.

This paper enriches the research that compares the use of modal verbs in hosts from different countries and helps to advance our knowledge about power relations hidden in the discourse. However, the time limit determines the small corpora of this study. Furthermore, the study source is based on the spoken English of five hosts who are not native English speakers, they are more likely to misuse modal verbs, which may influence the analysis results. The usage of modal verbs can be explored in different discourses such as in the political and legal context, which may reveal different results. Also, it is of research value to analyze the reasons behind the power relations from an interdisciplinary perspective like cross-culture and education.

\section{Conflicts of Interest}

The author declares no conflicts of interest regarding the publication of this paper.

\section{References}

Baker, P., Gabrielatos, C., KhosraviNik, M., Krzyżanowski, M., McEnery, T., \& Wodak, R. (2008). A Useful Methodological Synergy? Combining Critical Discourse Analysis and Corpus Linguistics to Examine Discourses of Refugees and Asylum Seekers in the UK Press. Discourse \& Society, 19, 273-306. https://doi.org/10.1177/0957926508088962

Biber, D., Johansson, S., Leech, G., Conrad, S., \& Finegan, E. (1999). Longman Grammar of Spoken and Written English. Longman.

Blommaert, J. (2005). Discourse: A Critical Introduction. Cambridge University Press. https://doi.org/10.1017/CBO9780511610295

Eggins, S. (2004). An Introduction to Systemic Functional Linguistics (2nd ed.). Continuum.

Fairclough, N. (1989). Language and Power. Longman.

Fairclough, N., \& Wodak, R. (1997). Critical Discourse Analysis. In T. A. Van Dijk (Ed.), Discourse Studies: A Multidisciplinary Introduction (pp. 258-284). Sage.

Feng, Z. X. (2011). Modality in Systemic Functional Linguistics: Logic, Semantics, and Pragmatics. Foreign Language Education, 35, 1-5. 
Fowler, R. (1987). Notes on Critical Linguistics. In R. Steele, \& T. Threadgold (Eds.), Language Topics: Essays in Honour of Michael Halliday (pp. 45-64). John Benjamins. https://doi.org/10.1075/z.lt1.76fow

Fowler, R., Hodge, B., Kress, G., \& Trew, T. (1979). Language and Control. Routledge \& Kegan Paul.

Guo, S. (2011). Corpus-Based Critical Discourse Analysis. Journal of Tianjin Foreign Studies University, 5, 12-17.

Halliday, M. A. (1970). Functional Diversity in Language as Seen from a Consideration of Modality and Mood in English. Foundations of Language, 6, 322-361.

Halliday, M. A. (1994). An Introduction to Functional Grammar (2nd ed.). Edward Arnold.

Halliday, M. A., \& Matthiessen, M. I. (2004). An Introduction to Functional Grammar (3rd ed.). Edward Arnold.

Halliday, M. A., \& Matthiessen, M. I. (2014). Halliday's Introduction to Functional Grammar (4th ed.). Routledge.

Hart, C. (2010). Critical Discourse Analysis and Cognitive Science: New Perspectives on Immigration Discourse. Palgrave MacMillan. https://doi.org/10.1057/9780230299009

Hodge, R., \& Kress, G. (1974). Transformations, Models and Processes: Towards a Useable Linguistics. Journal of Literary Semantics, 3, 5-22. https://doi.org/10.1515/jlse.1974.3.1.5

Hofstede, G. (2001). Culture's Consequences: Comparing Values, Behaviors, Institutions and Organizations across Nations (2nd ed.). Sage Publications.

Huang, G. W. (2001). Discourse Analysis. Foreign Languages and Their Teaching, 12, $1-4$.

Ji, Y. H., \& Chen, Y. (2007). A New Method of Critical Discourse Analysis: Critical Metaphor Analysis. Journal of Xiamen University (Arts \& Social Sciences), 6, 42-48.

Kandil, M. A. (2009). The Israeli-Palestinian Conflict in American, Arab, and British Media: Corpus-Based Critical Discourse Analysis. Georgia State University.

Lakoff, G. (1973). Hedges: A Study in Meaning Criteria and the Logic of Fuzzy Concepts. Journal of Philosophical Logic, 2, 458-508. https://doi.org/10.1007/BF00262952

Li, J. Y., \& Li, H. Y. (2014). Advances in Critical Discourse Analysis and New Reflections on Problems in It. Journal of Foreign Languages, 37, 88-96.

Lyons, J. (1977). Semantics. Cambridge University Press.

Martin, J. R., \& Rose, D. (2007). Working with Discourse: Meaning beyond the Clause (2nd ed.). Bloomsbury Academic.

Mazibuko, N. C. (2017). Checkmating the Mate: Power Relations and Domestic Violence in a South African Township. South African Review of Sociology, 48, 18-31. https://doi.org/10.1080/21528586.2016.1219967

Meyer, M. (2001). Between Theory, Method, and Politics: Positioning of the Approaches to CDA. In R. Wodak, \& M. Meyer (Eds.), Methods of Critical Discourse Analysis (pp. 14-31). Sage. https://doi.org/10.4135/9780857028020.n2

Miao, X. W. (2016). Systemic Functional Approach to Critical Discourse Analysis. Shandong Foreign Language Teaching, 37, 10-17.

O’Halloran, K. (2003). Critical Discourse Analysis and Language Cognition. Edinburgh University Press.

Palmer, F. R. (1990). Modality and the English Modals. Longman. 
Qian, Y. F. (2010). Corpus and Critical Discourse Analysis. Foreign Language Teaching and Research, 3, 198-202.

Salama, A. H. (2011). Ideological Collocation and the Recontexualization of Wahhabi-Saudi Islam Post-9/11: A Synergy of Corpus Linguistics and Critical Discourse Analysis. Discourse \& Society, 3, 315-342. https://doi.org/10.1177/0957926510395445

Schneck, S. F. (1987). Michel Foucault on Power/Discourse, Theory and Practice. Human Studies, 10, 15-33. https://doi.org/10.1007/BF00142984

Shen, J. R., \& Xin, B. (2016). Two Inclinations, One Integration: The Integrative Study of Critical Discourse Analysis and Cognitive Linguistics. Shandong Foreign Language Teaching, 37, 19-26.

Simpson, P. (1993). Language, Ideology and Point of View. Routledge.

Stubbs, M. (1996). Text and Corpus Analysis: Computer-Assisted Studies of Language and Culture. Blackwell.

Stubbs, M. (1997). Whorf's Children: Critical Comments on Critical Discourse Analysis. In A. Ryan, \& A. Wray (Eds.), Evolving Models of Language (pp. 100-116). Multilingual Matters.

Sweetser, E. (1990). From Etymology to Pragmatics-Metaphorical and Cultural Aspects of Semantic Structure. Cambridge University Press.

https://doi.org/10.1017/CBO9780511620904

Tang, L. P. (2011). The Potentials of Corpus Linguistics in Strengthening Critical Discourse Analysis. Journal of Foreign Languages, 34, 43-49.

Van Dijk, T. A. (1988). News as Discourse. Lawrence Erlbaum.

Van Dijk, T. A. (2001). Multidisciplinary CDA: A Plea for Diversity. In R. Wodak, \& M. Meyer (Eds.), Methods of Critical Discourse Analysis (pp. 95-120). Sage. https://doi.org/10.4135/9780857028020.n5

Widdowson, H. (1998). The Theory and Practice of Critical Discourse Analysis. Applied Linguistics, 19, 136-151.

Wodak, R., \& Meyer, M. (2001). Methods of Critical Discourse Analysis. Sage. https://doi.org/10.4135/9780857028020

Wodak, R., \& Meyer, M. (2009). Methods for Critical Discourse Analysis (2nd ed.). Sage.

Xin, B. (2004). Critical Discourse Analysis: Criticism and Discussion. Journal of Foreign Languages, 5, 64-69.

Young, L., \& Harrison, C. (2004). Systemic Functional Linguistics and Critical Discourse Analysis: Studies in Social Change. Continuum.

Zhang, H., \& Jiang, L. (2008). Integration of Cognitive Linguistics and Critical Discourse Analysis. Foreign Language Research, 5, 12-19.

Zhang, L. (2011). Researches on Metaphor in the Paradigm of Critical Discourse Analysis. Shandong Foreign Language Teaching, 32, 30-33.

Zhang, R. (2015). Integration of Cognitive Linguistics and Critical Discourse Analysis: A Case Study of Profile and Construal Operation. Foreign Language Research, 32, 34-41.

Zhao, S. Q. (2001). Desire for and Anxiety about Contemporary Female Speech Authority. Journal of Social Science of Hunan Normal University, 2, 78-82.

Zhu, T. T. (2009). Cognitive and Social Integration-Reviews on Metaphors We Live by. Journal of Suzhou University (Philosophy \& Social Science), 30, 64-66. 